\title{
What we learned from a medical education elective program at a medical college
}

\author{
Wookjin Oh, Jaeyoung Choi, Jungmin Lee, Raeyoon Jeong and Sangseok Oh \\ Department of Medicine, Korea University College of Medicine, Seoul, Korea
}

\section{Introduction}

Korea University College of Medicine provides finalyear students with an elective course titled "Career exploring," which helps students broaden their perspectives and explore diverse career paths, including clinical practice and other related fields. The authors selected a medical education elective course to explore how medical education theories have evolved into an actual curriculum. In 2018, Korea University College of Medicine underwent a major curricular reform, and the students' reactions were not favorable. The authors were also anxious while experiencing the changes and unintended negative effects. We, the authors, were puzzled by questions such as "Why are these changes being made? What is the purpose of these changes?" Another question we embraced was, "To resolve our questions and have the opportunity to participate in curriculum improvement, is it necessary to study medical education as a formal course, beyond our interests?" The 2-week medical education elective course provided us with the opportunity to answer such questions. We would like to share the experiences and thoughts we had during this elective course. In the first part of this commentary, we will describe the authors' perspectives on the rationale for why studying medical education is a worthwhile experience for students, along with our suggestions for improving the medical curriculum, based on what we learned from the course.

During the course, we iteratively discussed and contemplated the reasons medical students study medical education. The answers we came across are the followings. First, we all agreed that every doctor is someone's teacher. They inevitably teach what they know to patients, juniors, colleagues, and other healthcare professionals. Residency trainees in university hospitals should be involved in clerkship student education. Furthermore, all doctors should maintain a good image as a doctor as well as their academic knowledge. Therefore, the authors suggest that studying medical education will prepare us to be good teachers and
Received: May 31, 2020 • Revised: July 8, 2020 • Accepted: July 22, 2020 Corresponding Author: Wookjin Oh (https://orcid.org/0000-0002-8802-4298) Department of Medicine, Korea University College of Medicine, 73 Goryeodae-ro, Seongbuk-gu, Seoul 02841, Korea

Tel: +82.2.2286.1125 Fax:+82.2.2286.1104 email: wookjinoh21@gmail.com
Korean J Med Educ 2020 Sep; 32(3): 257-259.

https://doi.org/10.3946/kjme.2020.173

eISSN: 2005-7288

(C) The Korean Society of Medical Education. All rights reserved. This is an open-access article distributed under the terms of the Creative Commons Attribution Non-Commercial License (http:// creativecommons.org/licenses/by-nc/3.0/), which permits unrestricted non-commercial use, distribution, and reproduction in any medium, provided the original work is properly cited. 
educators.

Second, studying medical education enhances students' understanding of their curriculum and underlying school policy. During the course, we learned that medical schools must continue to change and innovate to fulfill the needs of society. Contemporary society requires that doctors be excellent clinicians but also that they develop many other qualities such as higher standards in professionalism and ethics to be good researchers, leaders, collaborators, and health advocates. To cultivate these qualities, significant curricular changes are inevitable, and it is a very challenging task to incorporate new things in an already crowded medical curriculum. We, the authors, came to know why our medical school made recent significant changes and understood that the unintended negative responses were inevitable by-products of curricular changes. Studying medical education can enable students to become more responsible stakeholders, not mere complainers as consumers.

Third, acquiring knowledge of medical education can increase student confidence when expressing their opinions on improvements to the curriculum and learning environment. Increased competency and confidence in education can help students speak up and more actively participate in the school's decisionmaking processes. Contemporary medical education has switched from teacher-centered to student-centered learning, including academic responsibility, individualized learning, and student participation in the decisionmaking processes of medical school [1]. There is increasing awareness that students are catalysts of curricular innovation and that it is important for them to be actively engaged [2-7]. Previous studies have raised issues concerning the current level of student involvement in medical school decision-making processes or curricular reforms. Student involvement is often restricted to passive feedback, or the opinions of student representatives [4]. Moreover, students have misgivings about new curricula [6], or feel uncomfortable communicating with faculty members because they lack a macroscopic perspective of the effort required to change it [7]. To overcome these issues and promote active student participation, we need a cooperative attitude between students and faculty members [5] and a shared understanding that the values of each party are equally important in the curriculum, so as to build trusting relationships through the experience of working together.

Now, we would like to share our ideas on curriculum improvement, based on what we learned in the 2-week course. First, our medical college offered an early clinical exposure course titled "Caring and compassion" for premedical students. Currently, this course operates at the university teaching hospital. We suggest that community-related activities should be incorporated into the course to identify and satisfy community needs. Moreover, a community-based program can be designed to encourage students to build teamwork and interpersonal skills by carrying out team projects. Second, we developed a revised curriculum for the clinical integrated course and proposed it to the authors' school. Our revision plan includes re-sequencing of integrated courses, according to degree of difficulty and interrelations between the subject matter and contents, based on the educational principles that we learned during the elective course. Our proposal has since been conscientiously discussed by the curriculum committee. Although our revision proposal is based on a simple curriculum design principle, it would be meaningful for student voices to be heard by the school and our proposal actually implemented next year. Finally, we would like to suggest that a "pass/fail" system (P/F system) of student assessment be seriously studied. 
Previous studies have reported that excessive competition can be alleviated through the P/F system and that it can promote student mental health and strengthen student solidarity [7,8]. All students can then accomplish their graduation outcomes through cooperation, rather than intense competition.

It is natural for medical students to be uninterested in medical education theory and practice, or underestimate its value. However, we would like to recommend medical education study to medical students, if they wish to build a better school by contributing their voices. Students can become more active, self-directed learners and achieve their educational outcomes, when they better understand how educational theory can be applied to their curriculum and why it is necessary. Furthermore, it may improve students' awareness as stakeholders in medical schools and enhance their engagement in school activities. Lastly, communication and cooperation between students and faculty members/medical schools can be enhanced through medical education study and experiences.

\section{ORCID:}

Wookjin Oh: https://orcid.org/0000-0002-8802-4298; Jaeyoung Choi: https://orcid.org/0000-0001-5209-5513; Jungmin Lee: https://orcid.org/0000-0003-4015-9684; Raeyoon Jeong: https://orcid.org/0000-0003-1382-0684; Sangseok Oh: https://orcid.org/0000-0003-1959-151X

Acknowledgements: We would like to express our thanks to Prof. Young-Mee Lee of the Department of Medical Education at the Korea University College of Medicine. She suggested that we present the lessons we learned during the medical education elective course and contributed to significant revision of the manuscript.

Funding: No funding provided for this research.

Conflicts of interest: No potential conflict of interest relevant to this article was reported.

Author contributions: All authors contributed equally to this work.

\section{References}

1. Harden RM, Laidlaw JM. Essential skills for a medical teacher. 2nd ed. London, UK: Elsevier; 2016.

2. Loeser H, O'Sullivan P, Irby DM. Leadership lessons from curricular change at the University of California, San Francisco, School of Medicine. Acad Med. 2007; 82(4):324-330.

3. Fujikawa H, Wong J, Kurihara H, Kitamura K, Nishigori $\mathrm{H}$. Why do students participate in medical education? Clin Teach. 2015;12(1):46-49.

4. Seale J, Gibson S, Haynes J, Potter A. Power and resistance: reflections on the rhetoric and reality of using participatory methods to promote student voice and engagement in higher education. J furth High Educ. 2015;39(4):534-552.

5. Burk-Rafel J, Harris KB, Heath J, Milliron A, Savage DJ, Skochelak SE. Students as catalysts for curricular innovation: a change management framework. Med Teach. 2020;42(5):572-577.

6. Bear AJ, Simpson D, Brown D, Bragg D, Marcdante K. Faculty and students perceive common tenets associated with medical student curriculum reform. Int J Med Educ. 2013;4:186-192.

7. Spring L, Robillard D, Gehlbach L, Simas TA. Impact of pass/fail grading on medical students' well-being and academic outcomes. Med Educ. 2011;45(9):867-877.

8. Rohe DE, Barrier PA, Clark MM, Cook DA, Vickers KS, Decker PA. The benefits of pass-fail grading on stress, mood, and group cohesion in medical students. Mayo Clin Proc. 2006;81(11):1443-1448. 